\title{
Japanese Student Ventures Born from Design Thinking Education
}

\author{
Tsuyoshi Aburai ${ }^{1}$ \\ ${ }^{1}$ Aichi Gakuin University Department of Management, Japan \\ Correspondence: Aichi Gakuin University Department of Management, 3-1-1 Meijo, Kita-ku,Nagoya,Aichi \\ 462-8739, Japan.
}

Received: May 18, 2021

doi:10.5539/ibr.v14n8p77
Accepted: July 9, 2021

Online Published: July 16, 2021

URL: https://doi.org/10.5539/ibr.v14n8p77

\begin{abstract}
For this project, I offer a case study of an entrepreneurship education program through industry-academic collaboration at a Japanese university. This program was launched in April 2018 in collaboration with a large, world-renowned company to provide students with opportunities to solve themes (problems) through design thinking. We will describe the processes involved in creating student ventures developed through this class, as well as the difficulties and challenges associated with these student ventures.
\end{abstract}

Keywords: design thinking, industry-university collaboration, student ventures, entrepreneurship education

\section{Introduction}

This article introduces the process by which students at a regional university in Japan started their own business as a result of design thinking education through industry-university collaboration.

The purpose of this project is to contribute to the development of educational activities and business by introducing the process of starting a business in chronological order, which is rare in Japan.

We will follow the process as shown in Figure 1.

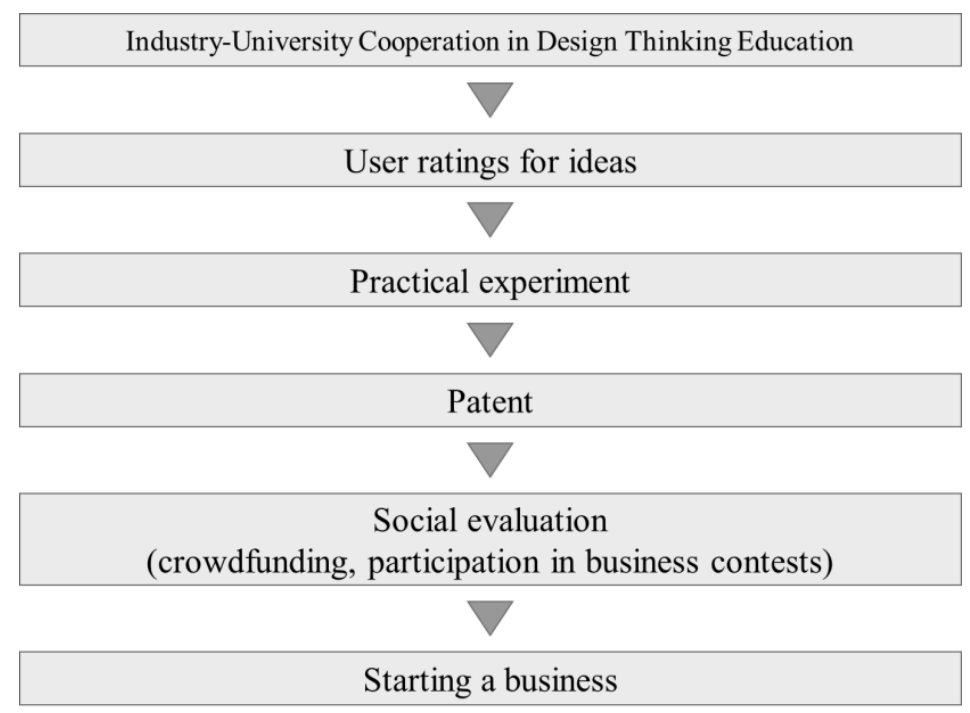

Figure 1. The Process of Starting a Business

\section{Design Thinking Education}

Design Thinking is a problem-solving method that starts from defining the problem, finding a solution, and delivering value. It is a popular approach that was initially introduced at Stanford University's d.school and the university's industry-academic collaboration class, ME 310. It is widely used in both the educational and the business sectors to develop new products and services and improve business operations. 
In recent years, Design Thinking has turned into a buzzword in business literatures that described it as a "user-driven" and "human-centered" approach. It resonates well with many people, given its uncomplicated way of positioning the user (person) at the center, allowing him to find the solution to the problem. It aligns well with the idea of a technology push that requires a manufacturer to make products using its own technology. Large companies are starting to embrace Design Thinkin, as traditional success patterns are no longer as effective in selling goods and services.

A human-centered approach is important as it is necessary to understand people's needs. The process of design thinking consists of five steps (Figure 2).

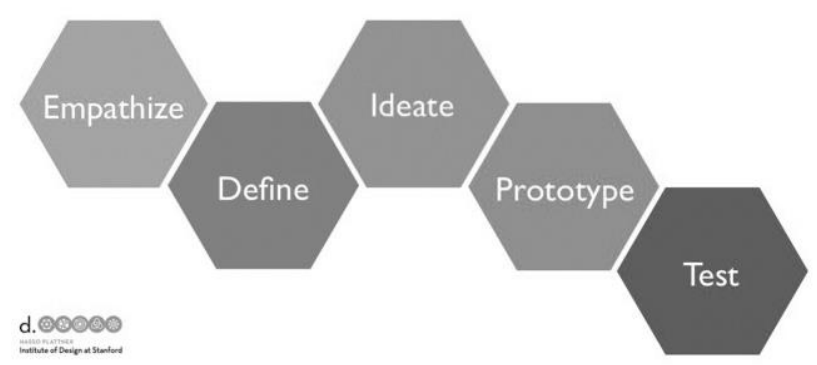

Figure 2. Process of design thinking (http://beyondthenexus.com/designthinking_empathy_innovation/)

The initial stage of the Design Thinking approach is Empathy, which means developing a solution by gaining an empathic understanding of the user. The first step is to observe, engage and use other means to gather substantial information about the users' problems. In addition, it is critical to generate ideas from experts to elicit knowledge that are useful in the problem-solving process. It is also important that the prototypes are properly documented for easier retrieval and testing of concepts. Assigned experts will examine these prototype ideas before delivering to the users for evaluation and testing. This step is aligned with the slogan "the user has the answer" and is rapidly rotated.

Learning about design thinking is a relevant undertaking among university freshmen. The typical classroom setting examination from elementary school to high school, and even in university entrance tests often requires students to "find the right answer". There is much more in learning design thinking, where students get to understand the users' problems through the "problem finding activity". The problem finding activity allows the learners to develop and nurture both a venture and research mind. The experience will be the start of a fruitful and meaningful student life. On the one hand, a venture mindset helps in developing a way of thinking that creates 1 from 0 . On the other hand, a research mind promotes an inquisitive mindset. Both these factors are important in performing the research concering the user's problems. While not everyone is inclined to start a business, developing a venture and research mindset is useful in various situations.

Design thinking approach is already adopted in many universities. Severalcase studies of company collaborations were published on the result of cooperation with the community and education sector.

\section{Entrepreneurship Education through Industry-Academia Collaboration}

In this paper, we present a case study of an entrepreneurship education program fostered through an industry-academic collaboration at a Japanese university. This program was launched in April 2018 in collaboration with a large, world-renowned company to apply a design thinking approach to solve the themes (problems) provided by the company. Our partner companies provided us with themes (issues) that have the potential of changing the world. An examination of the parameters of the issue helped us developed a big vision of creating value. In line with this program, the company created a new research and development department, tasked to participate in the project on the condition that they consider the commercialization of good ideas within the company. The program started in 2018, with 31 diverse students who belong to the first, second and third years of medicine, dentistry, science, and engineering department who were brought together to engaged in extracurricular activities. (Figures 3 and 4). 


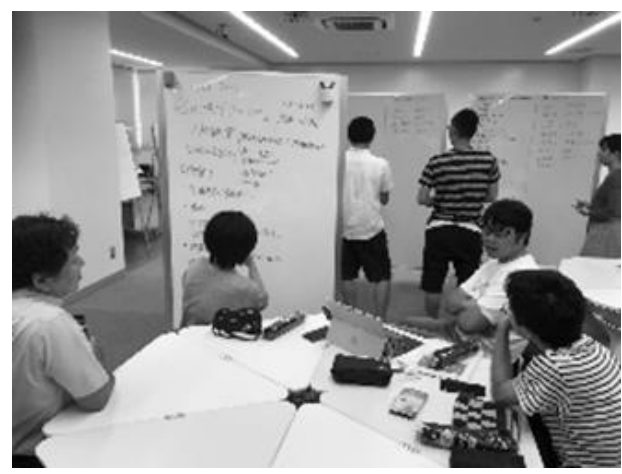

Figure 3. Workshops

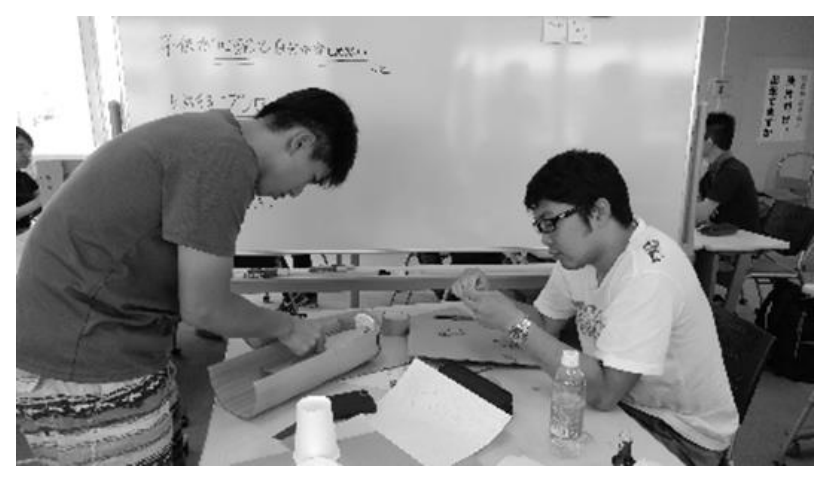

Figure 4. Prototyping

The themes of the four collaborating companies (JTEKT, Panasonic Cycle Technology, Yanmar and YKK) in 2018 are shown in Table 1. Each company were divided into five to ten people and worked from May to November.

In 2019, 21 students took the course as a general education class and it started in 2019. The themes (issues) are shown in Table 2, and the same schedule as last year was followed.

Table 1. 2018 Issues (Themes)

\begin{tabular}{|l|l|}
\hline \multicolumn{1}{|c|}{ Company name } & \multicolumn{1}{c|}{ Issues (Themes) } \\
\hline JTEKT Corporation & Bearing-Based Consumer Products and Business Models \\
\hline Panasonic Cycle Technology Co., Ltd. & Electrically Assisted Bicycles Changing Rural Transportation Infrastructure \\
\hline YANMAR Co., Ltd & $\begin{array}{l}\text { Autonomous Bird Repellent Robot : Scaring away ducks that approach the } \\
\text { natural grass }\end{array}$ \\
\hline YKK CORPORATION & $\begin{array}{l}\text { Development of applications for self-propelled fasteners : A small motor is } \\
\text { attached fasteners and controlled remotely by a smartphone. }\end{array}$ \\
\hline
\end{tabular}

Table 2. 2019 Issues (Themes)

\begin{tabular}{|l|l|}
\hline \multicolumn{1}{|c|}{ Company name } & \multicolumn{1}{c|}{ Issues (Themes) } \\
\hline JTEKT Corporation & A new sport that combines man and machine \\
\hline NH Foods Ltd. & Highly fashionable and well-designed gifts for the millennium generation \\
\hline $\begin{array}{l}\text { Panasonic Cycle Technology Co., } \\
\text { Ltd. }\end{array}$ & Human-powered rolling things \\
\hline YANMAR Co., Ltd & Exciting rides for a wide range of age groups at the resort \\
\hline YKK CORPORATION & Ideas for using electric snaps \\
\hline
\end{tabular}

In the years 2018 and 2019, the final deliverables include posters, prototypes, and videos for storytelling). In both years, the results were debriefed as an exhibition for companies and as a session of the Society for Innovation Education, respectively (Figures 5 and 6). The contents of the workshop consisted of solution presentations and poster/prototype exhibitions.

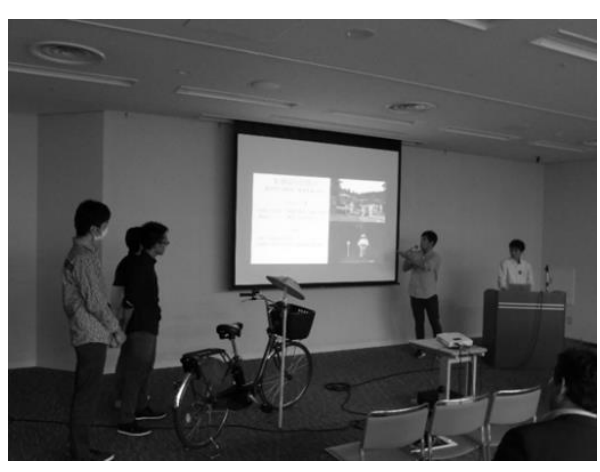

Figure 5. Results Presentation (2018)

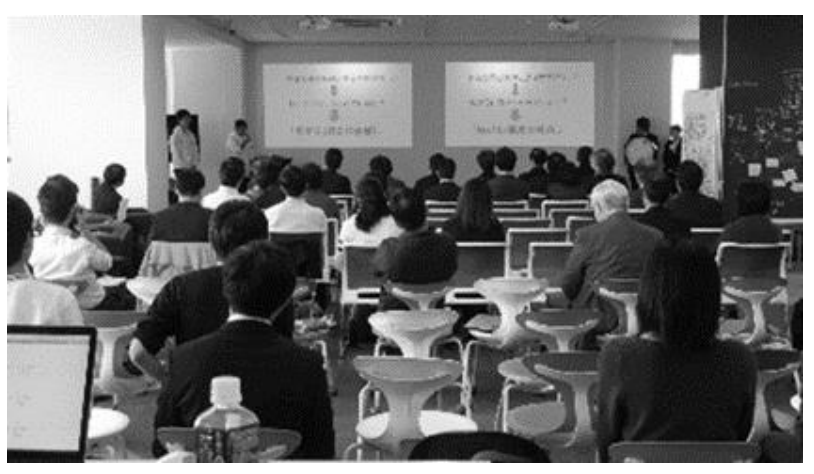

Figure 6. Results Presentation (2019) 


\section{Collaboration and Social Evaluation}

In 2018, students worked on a challenge provided by JTEKT entitled "Bearing-Based Consumer Products and Business Models ". In this challenge, the students found that visitors are not likely to pay attention to animals that do not move in summer and winter. The students decided to develop a "feeding device" as a solution.

The feeding system was made in cooperation with JTEKT and the zoo in Kagawa Prefecture, who provided constractive and useful feedbacks to the students after an evaluation.

Specifically, the zoo allowed us to perform a demonstration experiment. Finding a place to perform experiments on animal species can be challenging, but zoo administrators agreed to cooperate. The JTEKT team provided us with the technical support, including the trial manufacture of the feeding system.

Six student volunteers held the prototype in their hands from November 2018 to March 2019. We evaluated 100 participants including elementary school students and their parents to determine interest in using the feeding device. The result showed that about $78 \%$ of the participants expressed willingness to do so (Figure 7).

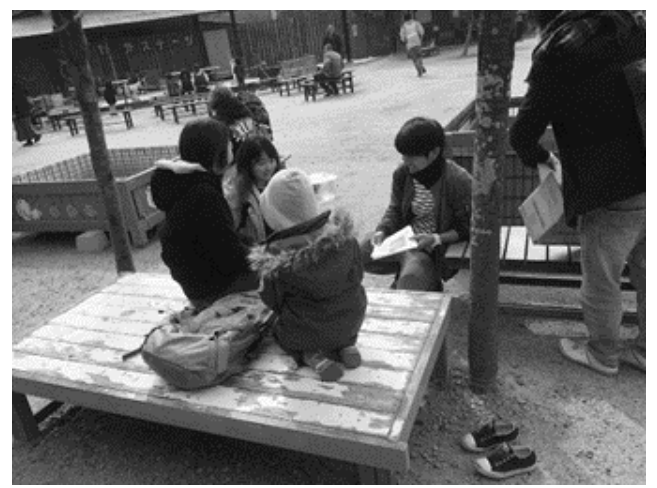

Figure 7. Holding a prototype in hand for user evaluation

In April, we conducted a demonstration experiment to measure the safety of and interest in Japanese macaque monkeys. This experiment led to the introduction of the feeding device.

In July, we conducted a crowdfunding campaign to support our activities and raised 860,000 yen, an amount higher than our goal of 800,000 yen. Our team received social recognition for this activity and gained 70 supporters in the process.

So far, we received seven awards in five contests, including a first prize award in the nationwide student business contest in November. Further, the mass media covered our experiment. A newspaper reporter informed us that animals in the zoo are often overstressed due to lack of exercise. In contrast to wild elephants and giraffes in the wild, elephants and giraffes in zoos have shorter lifespan. Reports further reveal that other animals, such as monkeys injure themselves due to stress.

\section{Establishing a Student Venture}

On November 18, 2019, the KAI, Inc, a student venture was established from the entrepreneurial education program through industry-academic collaboration. After the social evaluation through crowdfunding and business contests, we agreed to confirm the value of the student venture, and prepared for the start-up in August.

The company is a joint stock company headed by a current student. In Japan, it is very rare for a 20 -year-old sophomore student to hold the position of a president and director of the company, and both of them are listed in the patents. The main business domain is the development and sale of feeding devices and systems, zoo equipment, and exercise promotion systems.

In December, we started operation and installed an actual feeding device at a zoo (Figures 8-10). In this business model, free feeding equipment are provided to zoos and part of the revenue is generated from visitors who pay for cost of soybeans, red beans, pellets, and other foodstuffs fed to the animals. We also plan to develop a new feeding system for aquariums. 


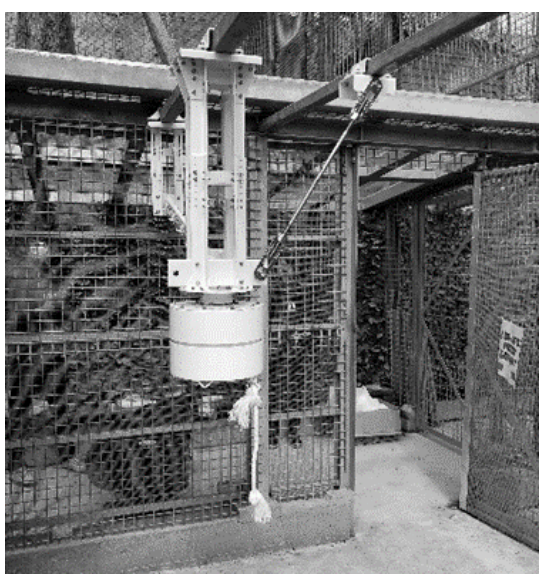

Figure 8. Feeding equipment installed in a zoo

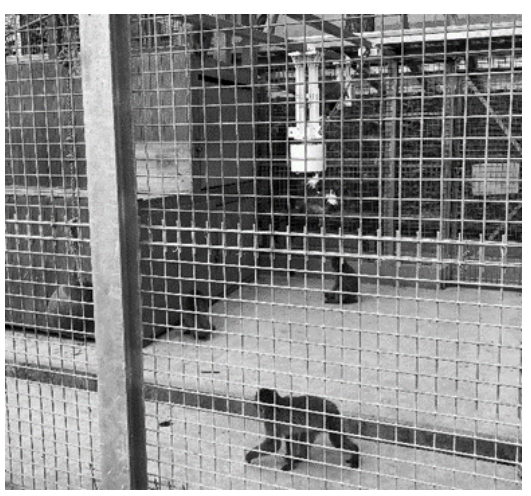

Figure 9. Monkeys exercising on a feeder

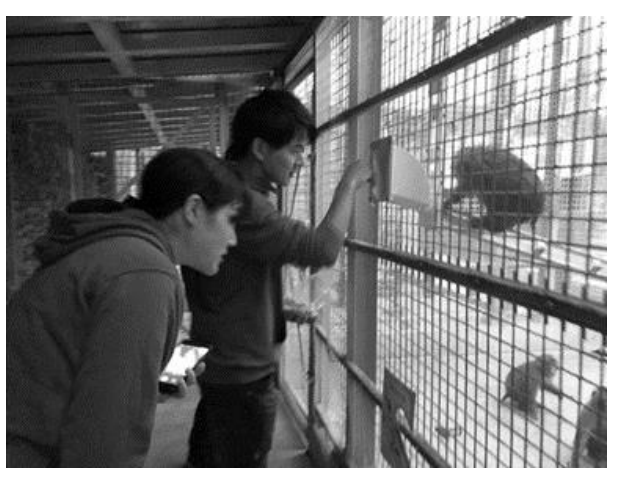

Figure 10. Feeding from outside the monkey house

\section{The Difficulty of Student Entrepreneurship}

A part of the strategy to invigorate Japan's economy includes the promotion of opening new businesses, especially venture companies. At present, many universities offer courses in entrepreneurship to broaden the base of those who want to venture into entrepreneursship.

However, entrepreneural practice rate in Japan remains low and we have made minimal progress. The Japanese government's growth strategy is to have the opening rate of 4 percent exceed the closure rate of 7 percent. It also aimed to achieve the 10 percent opening the United States and the United Kingdom. However, the current situation is unchanged from the growth strategy established in 2013. That is, the opening rate remains below 5 percent, rather than the goal of 10 percent opening rate in 2020. Moroever, the rate of business closures is increasing every year. Analyst pointed out that the low rate of entrepreneurship in Japan is associated with the fact that entrepreneurship is not an occupational option and that it is not widely accepted in society.

An analysis of a Global Entrepre-neurship Monitor survey shows that by international comparison, the level of penetration of entrepreneurial activities in Japan is around 17\%, while the average rate in developed countries is 30 percent. The country's average ownership rate of the U.S. Treasury is $13 \%$, which is low compared to $41 \%$ in developed countries. The substantial difference in the rate of entreprepreneurship suggests that there are bariers to starting a new venture, some of which includes lack of motivation to start a business, unfamiliariaty, and lack of knowledge about entrepreneurship. As the situation suggests, Japan's entrepreneurship education has yet to sufficiently responded to the want for entrepreneurial knowledge in the country.

In recent years, universities in Japan started to focus on entrepreneurship education, and we believe that people with entrepreneurial mindset can help enlighten others through lectures and other events. Still, considering the decline in the opening rate, we believe that it is time that universities adopt a new learning approach.

A survey by the Japan Finance Corporation (JFC) suggess that some of the common reason for not starting a new business includes a) Lack of personal funds at $53.1 \%$, b) High risk of failure at $35.5 \%$, and c) Cannot think of a 
business idea" at 8 percent. In its Report of the Advisory Committee on Venture Capitalism, the Ministry of Economy, Trade and Industry cited that the low entrepreneurial activity in Japan is attributed to lack of cooperation with large companies. Thus, the accumulation of concrete, hands-on entrepreneurship education methods to remove these disincentives to entrepreneurship has become an important social issue.

While recognizing these social problems, the faculty members in charge of the project must have felt firsthand the difficulties of student entrepreneurship. Based on the author's experience, the reasons why it is difficult to start a business as a student are summarized in the following six paragraphs.

1) Not enough time to graduate.

Both students and faculty have to think about how many more months they can work before graduation. Naturally, he cannot work during the exam period. In the summer of junior year, students are aware of internship opportunities, and senior year students are in the mood for job hunting rather than starting a business. In many cases, Japanese companies do not appreciate this challenge, even if they try to start a business and in the worst case, lose their jobs.

2) The pitfalls of community building

Despite their entrepreneurial-mindedess, some students are not likely start a business on their own. Even after gathering in a coworking space and talking about their dreams with other like-minded people, students face the reality of job hunting as they approach their senior year. This may cause a sudden drop in their motivation to start a business. It is therefore important to get public recognition for the place where students can talk about their goals and dreams.

3) Focus and selection of conscious students

It is often difficult to achieve the same level of learning quality when educating more than 100 students. It is important to find students who show strong desire to venture into entrepreneurship and motivate them early on. For instance, under this program, the institution can find first and second year- students who are interested to take on the journey towards entrepreneurship. While 3rd and 4th year students are good candidates for the program, studies indicate that they are most likely focused in job hunting.

4) Start-up funds

Approximately 700,000 yen is needed for the first year of operation, which may include cost of company registration, website and domain name registration, business card production, tax accountant's advisory fee, corporate inhabitant tax, rent and utility expenses. It is difficult for individual students to start their own business without parental support. In this paper, we show that a private university's school corporation is more likely to have an equity stake in a private university if it is closely connected to the university's activities. On the other hand, public university corporations can own shares if they receive donations, but cannot invest in them. In this case, it is necessary to establish an external organization and a mechanism to invest in it.

\section{5) Shared vision}

In this paper, we propose a new business model for students by the time they turn 20 . There were many instances where people try to invite their friends to join the company either as employees or as members of the board of directors. However, disagreement with the CEO's ideas and management strategies often prevent these people from pursuing a career in the company. While failure is a very good process for success, it may demotivate people from starting a business as their drive is lost with the failure. We recognized the challenges in generating a business idea, but this can be resolved with the use of the theme through industry-academic collaboration. We believe that the user-driven vision acquired through learning design thinking as a team can strengthen the entrepreneurial spirit.

6) Adult Involvement.

Students cannot create a business plan, obtain funds, behave as a member of society, or cooperate with companies by themselves. Adult support for students to maximize their flexibility of thinking and action in a limited amount of time will help them toward entrepreneurship.

\section{Future plans}

Kagami (2011), a leading expert on entrepreneurship education, describes in detail the situation of venture development in universities and the methodology of entrepreneurship education. He points out the importance of improving the environment inside and outside the university, such as the a) organizational structure for industry-university collaboration in venture development, b) University of Tokyo's Entrepreneurial Training 
Program University of Tokyo Entrepreneurial Dojo, and c) collaboration with the University of Tokyo Edge Capital (UTEC). Kumano (2014) proposed three types of entrepreneurship for the common understanding of venture firms (Table 3). This needs to be clarified, as it is still unclear which type of business startups are based on industry-academic collaboration.

Table 3. Type of Entrepreneurship

\begin{tabular}{|l|c|c|c|}
\hline & Venture-type & Small to medium enterprises-type & Self-employed-type \\
\hline Funding & Investment & Financing & Financing \\
\hline Employment & $\bigcirc$ & $\bigcirc$ & $\times$ \\
\hline Growth potential & Rapid growth & Low growth & Low growth \\
\hline
\end{tabular}

Table 4. Entrepreneurship Education through Industry-Academia Collaboration

\begin{tabular}{|l|c|c|}
\hline \multicolumn{1}{|c|}{ Items } & So far & From now on \\
\hline $\begin{array}{l}\text { Awareness on the part of } \\
\text { companies }\end{array}$ & Confinement & Freedom \\
\hline Theme & Helping Companies & Social Impact \\
\hline Educational methods & Systems thinking & Design thinking \\
\hline Team & A few & Diversity \\
\hline Target group & $\begin{array}{c}\text { Undergraduate } 3 \text { years to graduate } \\
\text { students }\end{array}$ & $\begin{array}{c}1 \text { to 2 years for undergraduate } \\
\text { students }\end{array}$ \\
\hline Vision of Management & Generalist & Specialist \\
\hline Money & Accounting & Finance \\
\hline Evaluation & On campus & Off campus \\
\hline
\end{tabular}

1) Awareness on the part of companies

We have seen situations where companies tell students that they have a goal to achieve and guide students' ideas while they are allowed to 'set them free'. It is important to expect flexible thinking in the future and encourage companies to be less involved and less advisable to engage in truly free activities.

2) Theme

For example, students may not be motivated to create pamphlets for a company, which would be outsourced to a design firm. The plan should be designed to leave an impact on society and lead to activities such as social recognition through participation in business competitions.

3) Educational methods

We want to develop human resources who can find problems by design thinking, not by systems thinking, which connects elements that already have problems and interact with each other.

4) Team.

It may seem extreme, but it is wiser to think together than to think alone. Furthermore, we want to team up with people outside of our area of expertise and expand our ideas.

5) Target group

Third year students to graduate students are ideal for industry-academic collaboration based on the seeds of the laboratory, but entrepreneurship education should target the first year or two before the mood of job hunting.

6) The image of the manager you aim for

Train generalists, who are leaders and involved in any type of work, to become specialists who know their weaknesses, learn what they lack, and then leave it to others.

7) Your money

You should pay for a tax accountant where you can, and as a manager you should learn finance such as capital policy that will make your company grow. First, it is important to understand the difference between financing and investment.

8) Evaluation 
The decision to accept or reject an idea solely on the part of the person in charge of the university or its partner companies should be abandoned. We should seek evaluation outside of academia, such as crowdfunding and business contests, to let users evaluate the viability of ideas.

Thus, entrepreneurship education through industry-university collaboration has just started. I would like to contribute to the economic revitalization of our country by gaining knowledge from the case of KAI Corporation and previous research on entrepreneurship.

\section{References}

Growth strategy portal site for small and medium-sized businesses and small business productivity enhancement. Retrieved from https://www.kantei.go.jp/jp/singi/keizaisaisei/portal/SMEs/policy.html

KAI.inc. Retrieved from https://www.kai-jp.com/

Kumano, M. (2014). Realization of Venture Entrepreneurship Society: Construction of Entrepreneurship Education and Ecosystem, Nakanishiya Publishing.

Kumano, M. (2016). Creation of Venture Companies and Entrepreneurship Education: Sojo University Entrepreneurship Training Program, The Japan Finance Corporation (JFC), Vol. 30.

Kurokawa,T. (2012). Design Thinking Education in University and Over Graduated Course (In Japanese) (pp. 10-23). Science \& Technology Trends.

KYOTO INSTITUTE OF TECHNOLOGY, Design lab. Retrieved from http://www.design-architecture.kit.ac.jp/ja/de/outline.php?id=4

New Industry Office, Economic and Industrial Policy Bureau, Ministry of Economy, Trade and Industry: How to increase youth entrepreneurship? ～From the point of view of the venture back scheme, http://www.pref.kanagawa.jp/uploaded/attachment/792807.pdf

Saito, S., Sakamoto, H., Takeda, Y., Sumi, M., \& Ouchi, T. (2017). A Guide to Design Thinking for Engineers (In Japanese). Shoueisha Publishing.

Shigeo, K. (2011). University-launched Venture and Innovation, Toshiya Watanabe (ed.), "University and Human Resources as an Innovation System", Hakuto Shobo.

Stanford University's Hasso Plattner Institute for Design Studies. (2012). Stanford Design Guide: Five Steps to Design Thinking. in The Institute for Design Thinking (ed.)

Tokushima University Innovation Plaza. Retrieved from https://eci-tokushima-u.jp/

\section{Copyrights}

Copyright for this article is retained by the author(s), with first publication rights granted to the journal.

This is an open-access article distributed under the terms and conditions of the Creative Commons Attribution license (http://creativecommons.org/licenses/by/4.0/). 